\title{
MOBILE ADVERTISING AND PAYMENT: THE PRESENT AND FUTURE
}

\author{
Pankaj Nagpal, Central Connecticut State University,pxn18@case.edu \\ C. Christopher Lee, Central Connecticut State University, cchristopherlee@ccsu.edu \\ Kalle Lyytinen, Case Western Reserve University, kalle@case.edu
}

\begin{abstract}
In recent years, mobile advertising has shown strong growth. Apple, Facebook, and Google are key actors in this market. Mobile payment is a nascent field on the cusp of growth. Tech companies such as Apple, Google, and Samsung have announced their payment products. Along with smaller players, these interrelated markets comprise key networks that will affect the evolution of mobile space as an advertising and payment medium. We use Actor Network Theory (ANT) as a lens to study the coming 'wars' among versatile multi-technology companies such as Apple and Google and specialists such as Facebook and Samsung. While this well-reported categorization suggests vastly different strengths and disparate strategies, additional analyses suggest that there are some similarities among these four key players. Mobility-related networks have additional implications for so-called emerging markets where mobile phones have leapfrogged desktops as a device of choice. This paper also discusses theoretical implications, limitations, and conclusions.
\end{abstract}

Keywords: Mobile phones, Advertising, Strategy, Payment, Actor Network Theory.

\section{INTRODUCTION}

Mobile advertising and mobile payment are related and growing activities in the mobile and wider business ecosystem. While several restrictions on advertising have been in the limelight (Waters, 2015), the ability to allow mobile advertisements is in the hands of a small number of players. In this respect, Apple, Google, and Facebook are key companies in the actor network of the mobile telecom industry (Nagpal, 2014). Growth of mobile advertising has been well-documented (eMarketer.com, 2015b), and it appears that mobile will surpass well-known conventional media in the next few years. Developed markets, in regards to the use of smart phones, are key. Emerging markets where mobile telephones have served to connect large populations to the Internet for the first time (leapfrogging desktop computers entirely) hold attractive prospects for mobile advertising. Increased use of smart phones in these markets, owing to the introduction of low-cost handsets has improved the prospects of mobile advertising. Overall, the ubiquity of mobile phones in developed countries and the increased access to Internet via mobile phones in emerging markets have made mobile advertising an industry to watch. As a related industry, mobile payment has drawn the interest of a similar set of players (Calvey, 2014). Android Pay has recently launched, following Apple Pay and Samsung Pay.

Unlike in the smart phone wars (Nagpal, 2014), there are a number of similarities in this newly emerging industry that merit the use of similar theories and frameworks. First, these are competing networks. However, these are competing models that are set to clash at the intersection of the mobile and Internet industries. Extant research has examined the industries discretely, with well-known work on mobile advertising (Okazaki, Li, \& Hirose, 2009) and mobile payment (Mallat, 2007). However, the role of key common players in these related industries would suggest the role of networks, and hence Actor Network Theory (Gao, 2005) in the study of mobile advertising and mobile payment. Related work on mobile banking (Illia, Ngniatedema, \& Huang, 2015) has reviewed work on a wide range of theories to understand mobile banking and derive propositions from theory. This paper adds to this recent stream of work on the mobile-related industry.

In this paper, the Actor Network Theory (ANT) serves as a lens to view the subset of the mobile phone industry. The subsets relate to mobile advertising and payment. This paper analyzes the key actors or actants in the related industries of mobile advertising and payment and their interactions within actor networks. The article is organized 


\section{Issues in Information Systems \\ Volume 19, Issue 3, pp. 212-219, 2018}

first by starting with some background on each industry and actor network theory. That section is followed by a review of literature on mobile payment and mobile advertising. Brief analyses of the key players follow. The paper concludes with discussion, contributions, limitations, and suggestions for future research.

\section{INDUSTRY BACKGROUND}

\section{Mobile advertising}

Apple, Facebook, and Google have been mentioned as the leading players in mobile advertising (Waters, 2015). Recent developments include Facebook's Instant Articles, a mobile-focused initiative that the Washington Post and other outlets joined. The pros and cons of having such content available to a larger number of users, who do not need to reach the original source such as Washington Post, is a concern. Ad blocking is also an important development, widely discussed for its effect on mobile advertising. Unlike simply an absence of advertising (O'Reilly, 2015), the use of 'smart' filters can help users to control and select the advertisements to allow on their phones. In spite of the concerns related to ad blocking, the marketing community still has not felt the effect. The effect of ad blockers was not apparent to leading content providers after Apple started to approve such apps (Shields, 2015). At the same time, growth of mobile advertising was expected to account for more than half of all digital advertising expenditure (eMarketer.com, 2015b).

\section{Mobile payment}

As a technical term, "mobile payment" used to imply the use of a text message to a premium service number (Menke \& Lussanet, 2006). It has now evolved into point-of-sale and remote mobile payments. The former involves near field communication (NFC), while the latter involves texting or mobile Internet in the form of apps. Recently, Samsung has announced the success of its Samsung pay format, which goes beyond the NFC requirement. With a number of developments, the mobile payment market is expected to grow at well over $30 \%$ annually on transaction volume (TechNavio, 2015). Increase in awareness, and convenience, are the drivers of this anticipated growth. In spite of a number of concerns, it is expected that high growth will characterize this market, at least for the next few years. In addition to consumers, recent research has also considered the role of merchants (Cabanillas, Slade, \& Dwivedi, 2016). However, the focus has been on users and consumers (Hayashi, 2012). Even after trial, continued use tended to be slow for a few years (Jia, Hall, \& Sun, 2014). The consumer context has also been researched (Wang, 2006).

\section{THEORY, FRAMEWORK AND LITERATURE}

Actor Network Theory (ANT) is the lens used in this article to view ongoing developments in mobile advertising and payment. ANT is a well-known theory (Callon, 1986) applied to the mobile and telecom industry (Allen, 2004; Gao, 2005; Nagpal, 2014). An early and well-cited paper (Tatnall \& Gilding, 1999) has an excellent review and motivation for use of ANT. In this paper, Tatnall and Gilding advocated for ANT and presented their view for its use in phenomena involving technological innovation. A brief review of ANT and its application is provided in Nagpal (2014), where the basic framework and its application to mobile carrier, application developers, and mobile phone companies is introduced.

Actors and actants, as defined in ANT, are versatile tools for application to the telecom industry. In this respect, devices (Allen, 2004), standards (Gao, 2005), and services (in this paper) are actants in the application of ANT. To the extent that services are not independent of mobile phone companies, these actants have a different role in the network, as compared to, for example, carrier companies.

\section{Mobile advertising}

The literature on mobile advertising has researched individual users as well as advertisers. In an early study, Okazaki (2005) found that American companies were more motivated to use mobile advertising, but cited security and cost as key concerns. A survey in Japan (Okazaki et al., 2009) showed consumers concerns for privacy and risk, 


\section{Issues in Information Systems \\ Volume 19, Issue 3, pp. 212-219, 2018}

with preference for high regulatory control on mobile advertising. On the other hand, earlier research in China suggested that personalization could improve consumer attitudes $(\mathrm{Xu}, 2006)$. Recent work has suggested an integrated model, to consider hedonic and utilitarian aspects as a whole. Based on data from Korean users, the emotions and technology (Yang, Kim, \& Yoo, 2013) were seen to have a role in discerning information quality and other performance expectations. Finally, based on large scale samples, Bart et al. (Bart, Stephen, \& Sarvary, 2014) concluded that mobile display advertising of high involvement and utilitarian products increased consumer purchase intentions. Informativeness and credibility are key drivers of user attitude toward mobile advertising (Islam, Kang, \& Yang, 2013). Their work strongly suggests that the credibility of actors is important to understand the phenomenon.

\section{Mobile payment}

Considering a related and less-studied topic, there is some research on the salient aspects of mobile payment. Mallat (2007) found a number of situational, context dependent factors that led to consumer adoption. Barriers included premium pricing, complexity, and lack of threshold user volume. Trust and risk are seen as antecedents to mobile payment adoption (Xin, Techatassanasoontorn, \& Tan, 2015). On the consumer side, the law also has not caught up with technological developments yet (Martindale \& Hillebrand, 2012).

\section{KEY PLAYERS AND THEIR NETWORKS}

This paper studies the role of actors in mobile advertising and payment. As discussed earlier, Apple and Google are active in each industry. Facebook and Samsung are active in one industry each, viz. mobile advertising and payment. There are several other players differing across geographies that are not discussed here. The differences between Apple, with its tightly-controlled actor network (Nagpal, 2014), versus Samsung, for example, are also important factors.

While this does not suggest much of a role for carriers, they do have a role since advertising has to access the carrier network. In contrast, carriers have tended to do well in mobile payment. As an example, Airtel Money has collaborated with Uber to offer payment (IBNS, 2015). In view of the limited spread of ATM services, and leapfrogging of users directly to mobile Internet, such initiatives hold promise for carriers.

\section{METHODOLOGY}

The research method relies on secondary data collected from a number of sources. To an extent, Actor Network Theory (ANT) is also a research method. In his seminal book "Re-assembling the social" and also later papers where he provides several clarifications (Latour, 1996), this view is supported. As to the use of ANT in telecom, it has a long history. In addition to actors and actants, other concepts are also used, although they are less common. In line with this view, we reviewed coverage of key companies identified within each network. Several authors have worked in the field of technology management and have used this approach. With this approach, we used various indexes to find articles on the selected companies. We used additional keywords, such as "advertising". We selected outlets that are well known, or those that had the latest coverage of a specific topic.

\section{RESEARCH MODEL AND FINDINGS}

As shown in Figure 1, these companies are set to compete even more vigorously for users' time and advertisers' wallets. In this respect, features such as Instant Articles (Waters, 2015) are new features to attract users who would receive this information from Google, or the content providers, in an earlier era. High levels of trust, usefulness, and engagement are likely to attract user time. In turn, this can monetize into engaging advertising. Initiatives in this direction include iAd, and Apple News. To the extent that the mobile advertising ecosystem continues to evolve, companies that control the handsets (Waters, 2015) are expected to be in a strong position. 


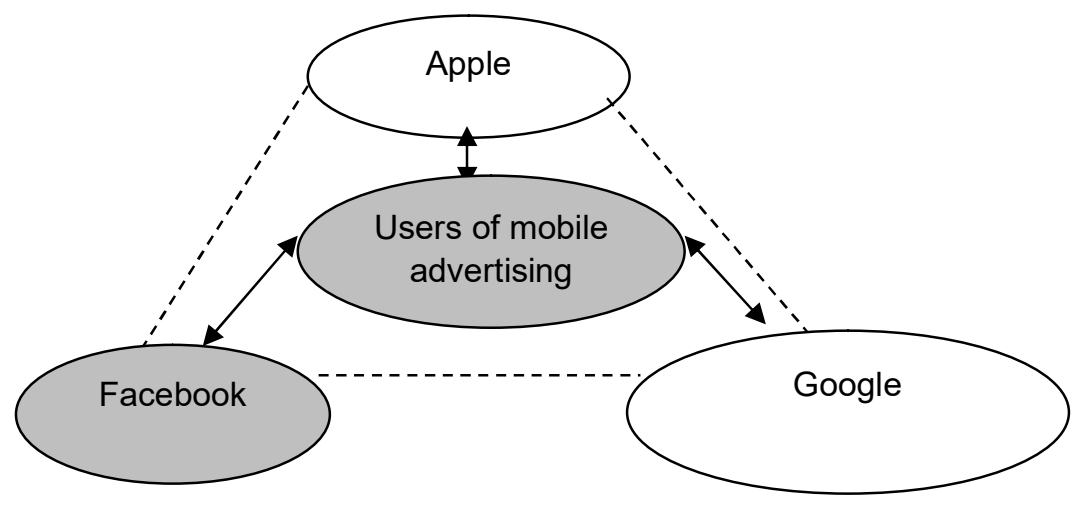

Figure 1. Mobile advertising network

Apple holds a unique position. As a handset and software maker with proprietary hardware and software, it is in a strong position to control the ecosystem around it. In this respect, it also draws on the strengths that have resulted in high profitability with successively higher prices on iPhones (reaching nearly one thousand dollars on iPhone X). With a loyal following that transcends social class and even nationalities, it is important to the network of mobile advertising. Recent monetization on the mobile (Levy, 2016) inevitably leads to competition with older players. In the above figure, dotted lines show interaction among Google, Apple and Facebook. However, the core of the network is composed of users, including both consumers and merchants. Their relationship with Apple can only get stronger with time. Google has been the leader in search engine advertising, and so its attempt to replicate this success in wireless space implies the weight of early success. For example, its share in mobile has been above $90 \%$ as per NetMarketShare (www.netmarketshare.com). It is important because these numbers claim to eliminate any fraudulent traffic that tends to cloud such measurement. For Facebook, mobile advertising has been an increasing share of its overall advertising revenues. In spite of privacy-related challenges, user engagement continues to grow. Given the time that users spend on their mobile phones, Facebook enjoys strong engagement with them. Security and privacy are important to Facebook, as it continues to engage its users.

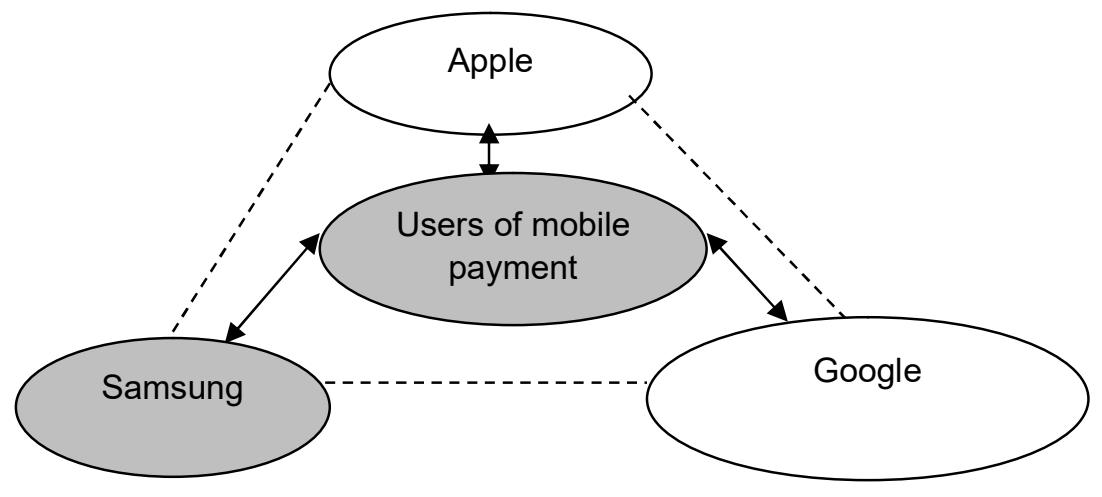

Figure 2. Mobile payment network

Apple Pay, Android Pay, and Samsung Pay are competing in different ways for the user's wallet. While Apple and Android use is dependent on the use of iPhone or Android phones respectively, Samsung pay represents a choice for Android users who have a specific Samsung phone model. Its exclusive technology goes beyond NFC, in that it simulates a card swipe and does not need NFC at the retail terminal (Gunther, 2015). Samsung pay has been reportedly a success in South Korea, and the company has provided data on its use. However, Android and Apple 


\section{Issues in Information Systems}

Volume 19, Issue 3, pp. 212-219, 2018

Pay have a head start in the United States. These leading providers also have a range of connections with retailers that will continue to evolve.

Apple has a strong position in that more than $30 \%$ of U.S. retailers now accept Apple Pay. In addition, several are getting ready to accept it in the next few years. Android Pay was a relatively weak concept, with the Android phone makers having their own mobile payment. Samsung Pay and LG Pay are examples. Google Pay has been a reset for the earlier Android Pay. Its integration with Gmail, for example, has potential to increase user level popularity. In addition, Google Pay has been used in ticketing. Google Tez is a payment app that has been introduced in selected countries and has drawn positive interest. In the long term, however, it is not clear how it will integrate or relate with Google Pay. Samsung Pay had a later start than Apple, but enjoys the advantage of being available everywhere at nearly all retailers. This was possible with the acquisition of a startup (Tibken, 2015). It has been rolled out in 20 countries, as per company release. Samsung emphasizes working with large and well-known financial companies, in view of the fact that credibility is important. As a promotion, "cash back" has been introduced to increase use. In view of Samsung's international footprint and experience with several countries, it is a strong competitor in this network.

A key difference in this network is that mobile payment competes with other legacy payments, including cash and credit cards. In some emerging markets, however, users are directly moving to mobile payment. This includes local startups that are relatively smaller, as compared to these leading companies. India and China, in particular, have a robust startup ecosystem.

\section{DISCUSSION AND CONCLUSIONS}

Starting with early work in telecommunications (Siau \& Shen, 2003), we have covered a lot of ground in theorizing through ANT. In view of our analyses and findings using ANT, there are similarities among players in mobile advertising and payment networks. However, the payment network is relatively more open and dynamic at this time. With several local players currently limited to specific countries or regions, e.g. China or India, this network is likely to evolve faster and in less predictable ways. It is a relatively dynamic network. In contrast, mobile advertising includes a smaller set of well-established companies that have a lot of resources to fight each other for a long time. A cross over to the other network is also possible. For example, the use of Facebook texting app to send money (Lanxon, 2017). Similarly, Google has also added a similar capability to its email.

\section{CONTRIBUTIONS, LIMITATIONS, AND FUTURE RESEARCH}

The analyses delve into new industries taking shape and changing the nature of marketing. According to a CMO article, "mobile will turn out to be the most transformative marketing tech we've seen in the past 30 years". While this might be hyperbolic, there are several developments that have only recently gained attention of researchers (Illia et al., 2015). As with this recent article, Actor Network Theory (ANT) holds potential explanatory power on the continuing development of several aspects of technology. First, it includes several actors and actants in a comprehensive model. Second, it is a dynamic model that incorporates qualitative and quantitative data at the same time. Finally, it builds on the initial study on 'types' of networks (Nagpal, 2014).

This approach has several limitations. The sources are limited to secondary data, although these sources tend to collect user level data in their research. Alternative approaches, as those used in Illia et al. (2015) complement our approach. Bias and errors in the reporting of secondary data are limitations in its use. 
There are several developments that are noteworthy. New entrants, or even existing companies, that start to emerge in similar technology are not covered in our analyses. Instagram, with its recent popularity in key demographics, is set to outperform existing leaders (eMarketer.com, 2015a).

\section{REFERENCES}

Allen, J. P. (2004). Redefining the network: enrollment strategies in the PDA industry. Information Technology \& People, 17(2), 171 - 185.

Bart, Y., Stephen, A. T., \& Sarvary, M. (2014). Which Products Are Best Suited to Mobile Advertising? A Field Study of Mobile Display Advertising Effects on Consumer Attitudes and Intentions. Journal of Marketing Research, 51(3), 270-285.

Cabanillas, F. L., Slade, E., \& Dwivedi, Y. (2016). Time for a Different Perspective: A Preliminary Investigation of Barriers of Merchants' Adoption of Mobile Payments. Paper presented at the AMCIS, San Diego, CA.

Callon, M. (1986). Some elements of a sociology of translation: domestication of the scallops and the fishermen of St Brieuc Bay. In J. Law (Ed.), Power, action and belief: a new sociology of knowledge? London: Routledge.

Calvey, M. (2014). Apple and Google seen flexing muscles in mobile payments. Bizjournals. Retrieved from http://www.bizjournals.com/sanfrancisco/blog/2014/04/apple-google-mobile-wallet-atpay-wells-fargo.html

eMarketer.com. (2015a). Instagram Mobile Ad Revenues to Reach \$2.81 Billion Worldwide in 2017. Retrieved from http://www.emarketer.com/Article/Instagram-Mobile-Ad-Revenues-Reach-281-Billion-Worldwide$2017 / 1012774$

eMarketer.com. (2015b). Mobile Ad Spend to Top \$100 Billion Worldwide in 2016, 51\% of Digital Market. Retrieved from http://www.emarketer.com/Article/Mobile-Ad-Spend-Top-100-Billion-Worldwide-201651-of-Digital-Market/1012299

Gao, P. (2005). Using actor-network theory to analyse strategy formulation. Information Systems Journal, 15(3), 255- 276.

Gunther, C. (2015). Android Pay vs Samsung Pay: What's the Difference? Gottabemobile. Retrieved from http://www.gottabemobile.com/2015/09/11/android-pay-vs-samsung-pay-whats-the-difference/

Hayashi, F. (2012). Mobile payments: What's in it for consumers? Economic Review-Federal Reserve Bank of Kansas City, 35-66.

IBNS. (2015). Airtel's Mobile Wallet 'Airtel Money' now accepted for Uber trips pan India. Sify News, (Sep. 15, 2015). Retrieved from http://www.sify.com/news/airtel-s-mobile-wallet-airtel-money-now-accepted-foruber-trips-pan-india-news-default-pjpaJidggfbee.html

Illia, A., Ngniatedema, T., \& Huang, Z. (2015). A Conceptual Model for Mobile Banking Adoption. Academy of Information \& Management Sciences Journal, 18(1), 111 - 122.

Islam, M., Kang, M., \& Yang, S.-B. (2013). A Research to Identify the Relationship between Consumers' Attitude and Mobile Advertising. Paper presented at the PACIS, Jeju Island, Korea.

Jia, L., Hall, D., \& Sun, S. (2014). The effect of technology usage habits on consumers' intention to continue use mobile payments. Paper presented at the AMCIS, Savannah, GA. 
Lanxon, N. (2017). Facebook to Make Mobile Payments Service Available Outside U.S. Bloomberg. Retrieved from https://www.bloomberg.com/news/articles/2017-11-06/facebook-to-make-mobile-payments-serviceavailable-outside-u-s website:

Latour, B. (1996). On actor-network theory: A few clarifications. Soziale Welt, 47(4), 369-381.

Levy, A. (2016). Apple wants a piece of the $\$ 100$ billion mobile ad market. $C N B C$. Retrieved from https://www.cnbc.com/2016/06/08/apple-wants-a-piece-of-the-100-billion-mobile-ad-market.html website:

Mallat, N. (2007b). Exploring Consumer Adoption of Mobile Payments - A Qualitative Study Journal of Strategic Information Systems, 16, 413-432.

Martindale, S., \& Hillebrand, G. (2012). Pay at Your Own Risk? How to Make Every Way to Pay Safe for Mobile Payments. Banking \& Finance Law Review, 27(2), 265.

Menke, L., \& Lussanet, M. D. (2006). SMS- Based Mobile Payments: Popular With The Young But Is There A Wider Mobile Payments Opportunity. Retrieved from http://www.forrester.com/Research/Document/Excerpt/0,7211,40678,00.html

Nagpal, P. (2014). Key Actors in the Mobile Phone Industry: The Smart Phone Wars. Academy of Information \& Management Sciences Journal 17(1), 87. doi:http://search.proquest.com/openview/5a019e1ea0d37d77f6f44f9d0ce9d9e5/1

O'Reilly, L. (2015). Ad blocking has grown $41 \%$ in the past year and it's costing publishers tens of billions of dollars Business Insider. Retrieved from http://www.businessinsider.com/pagefair-and-adobe-2015-ad-blockingreport-2015-8

Okazaki, S. (2005). Mobile advertising adoption by multinationals: Senior executives' initial responses. Internet Research, 15(2), 160-180.

Okazaki, S., Li, H., \& Hirose, M. (2009). Consumer Privacy Concerns and Preference for Degree of Regulatory Control. Journal of Advertising, 38(4), 63-77.

Shields, M. (2015). Apple Software Update Brings Ad Blockers Along With Apple News Sponsors Wall Street Journal. Retrieved from http://blogs.wsj.com/cmo/2015/09/16/apple-software-update-brings-ad-blockersalong-with-apple-news-sponsors/

Siau, K., \& Shen, Z. (2003). Mobile communications and mobile services. International Journal of Mobile Communications, 1(1-2), 3-14.

Tatnall, A., \& Gilding, A. (1999). Actor-Network Theory and Information Systems Research. Paper presented at the Australasian Conference on Information Systems.

TechNavio. (2015). Global Mobile Payment Market 2015-2019. Retrieved from https:/www.technavio.com/report/global-mobile-payment-market-2015-2019

Tibken, S. (2015). Samsung buys LoopPay, all but confirming new Apple Pay rival. CNET. Retrieved from https://www.cnet.com/news/samsung-buys-looppay-all-but-confirming-new-apple-pay-rival/ website:

Wang, A. (2006). When Synergy in Marketing Communication Online Enhances Audience Response: The Effects of Varying Advertising and Product Publicity Messages. Journal of Advertising Research, 46(2), 160-170. doi:10.2501/s0021849906060181

Waters, R. (2015, September 10, 2015). Apple, Facebook and Google flex mobile ad muscle. Financial Times. 


\section{Issues in Information Systems}

Volume 19, Issue 3, pp. 212-219, 2018

Xin, C., Techatassanasoontorn, A. A., \& Tan, F. (2015). Antecedents of Consumer Trust in Mobile Payment Adoption. Journal of Computer Information Systems, 55(4), 1-10.

$\mathrm{Xu}$, D. J. (2006). The Influence of Personalization in Affecting Consumer Attitude toward Mobile Advertising in China. Journal of Computer Information Systems, 47(2), 9-19.

Yang, B., Kim, Y., \& Yoo, C. (2013). The integrated mobile advertising model: The effects of technology- and emotion-based evaluations. Journal of Business Research, 66(9), 1345-1352. 